\title{
Innovations as an instrument for efficient municipal management
}

\author{
Yulia Boriskina $^{1, *}$ \\ ${ }^{1}$ Moscow State University of Civil Engineering, Yaroslavskoe shosse, 26, Moscow, 129337, Russia
}

\begin{abstract}
The article detects how innovations affect municipal development and management. Many fields of innovations used in cities are presented, showing the progress which have been reached by the cities in engineering, transportation and other areas. The article analyzes the main conditions and benefits from innovations implementation for city residents. As an example of innovative municipal project the author suggests the Smart city concept. The major elements of the Smart city concept are pointed out and detailed. The concept integrates all innovations and technologies into one system, providing possibility to practice efficient municipal management and to create a modern comfortable city environment.
\end{abstract}

\section{Introduction}

City population is growing very fast [1], creating new challenges for municipal management. Municipal authorities are responsible for engineering, housing, transportation, social and public places and conveniences. They have always been ready to use any inventions to fulfill their duties. Cities have always been a place, where new technologies spread quickly as it could facilitate everyday life for inhabitants. This was stimulated by both inhabitants themselves and the city government.

City technologies have developed enormously from gas lightening to sun-battery lights, from open street wells and stock to the network of city engineering providing fresh water and underground sewerage [2], from dusty roads to multi-level junction.

And now, when cities are entering new era of techno-ecological megapolises[3], new technologies and innovations become at hand as never before. Let's take a closer look at the new technologies which have appeared and try to figure out how they can by integrated for municipal management of the new megapolises and its inhabitants.

\section{New technologies and municipal management methods}

Innovations can be and are widely used by Municipal government in different areas.

First of all, innovations are of big use for municipal asset management, providing both better control and income. Land and properties registers are basis for taxes.

In London in order to stimulate housing and investment into construction Land Commission had been established. Under its governance a convenient map of brownfield

\footnotetext{
* Corresponding author: Boriskina@mail.ru
} 
land has been developed and now can be found at the city official website [4], showing information to potential developers, as Fig.1 shows.

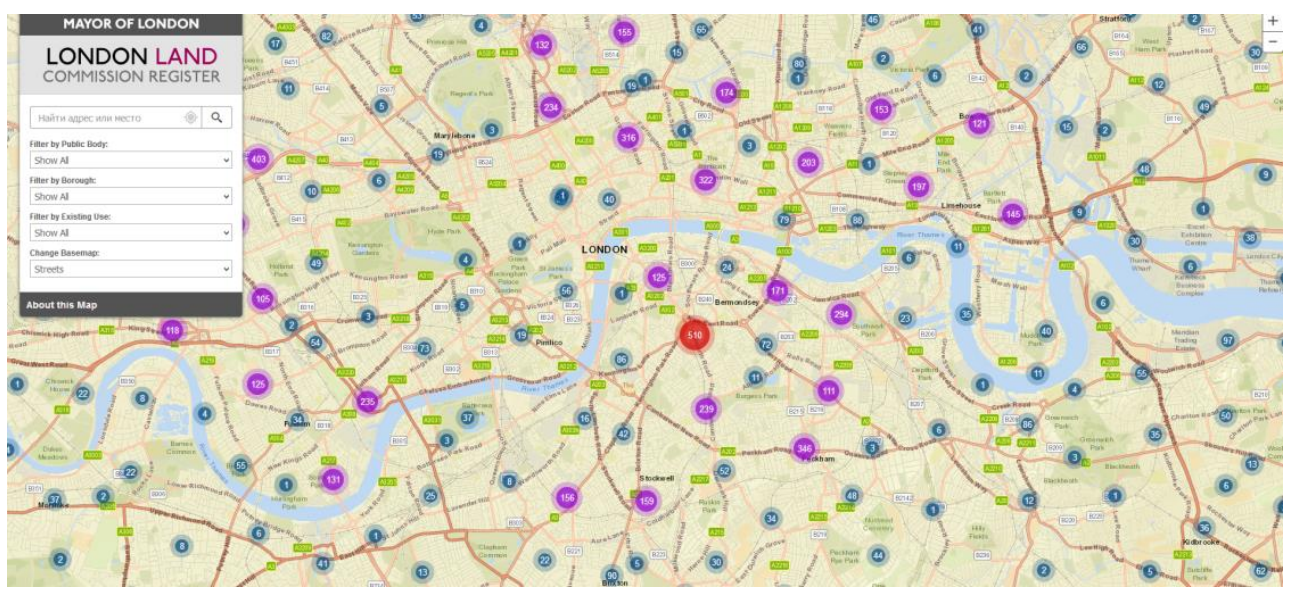

Fig. 1. London Land Commission Register.

Online tender system allows municipal institutions to choose best contractor, based on given characteristics. It eliminates personal factor and makes possible for distant contractors to take part in tender.

The auction online system is used to sell or rent from the city, attracting many interested participants.

Secondly, innovations are becoming an integral part of city engineering. Nowadays they regulate water pressure, heat temperature, energy consumption. Specially installed systems can show leakages and even stop them, saving water and money. Through analyzing water and energy consumption service companies can offer lower rates during low-consumption hours and plan network extension in order to meet growing demand.

Thirdly, the Internet and gadgets play essential role for more and more users. People work distantly and communicate via communicators, lab-tops etc. That is why now we can find WiFi e.g. in the Moscow underground, WiFi and USB-ports in parks, air-ports, railway stations and in public buildings in many cities all over the world.

Fourthly, technologies are integral part of city security system [5]. This includes not only people security via cameras in the street observing law and order, but also transport security via speed controllers. When emergency situation happen sms are send immediately.

Fifthly, the Internet and mobile application now - as never before - allow to have a quick feedback from citizens. For example, on the Moscow official site [6] there is a section "Active citizen" where one can leave his complaints or thanks, participate in volunteer voting on city planning and development issues.

Although it seems quite obvious that innovative technologies are warmly accepted by inhabitants, there are certain conditions that should be fulfilled [7]. The new technologies should be easy to use, easy to access and they should add comfort (Fig. 2).

The main goals of innovations implementation in municipal development are:

1) better and cheaper public and engineering services for residents

2) efficient usage of municipal budget and assets

3) modern and convenient public places and services

4) information data processing and analyzing

5) better ecology and smart resources consumption

All of the abovementioned includes the Smart city approach. 


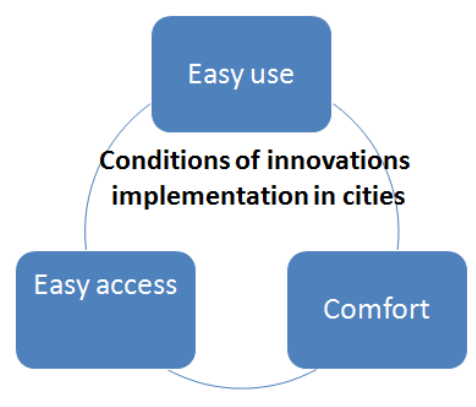

Fig. 2. Conditions of implementing innovations is cities.

\section{Results}

Technologies have been appearing gradually, one by one, whereas the most efficient way to implement them in municipal management is to integrate them into one system. The most progressive cities have already understood that and now are developing a new system [8]. This system is called the concept of Smart city.

The Smart city approach includes many elements, among the main ones we can name:

- Smart energy. The idea of energy consumption reduction is not new, but the digital and information technologies which are able to analyze and to advice how to do it more efficiently are quite new. It's impossible to underestimate movement sensors and sun-batteries, especially for housing in warm climate countries [9].

- Smart mobility. Smart mobility has several benefits. Public transportation is not only convenient for inhabitants, but also profitable for the city. The more comfortable and convenient it becomes, the more people choose is over personal cars. Mobile application are very useful helping to count destination time, arrival time, schedules, order a taxi.

Even for car drivers there are obvious conveniences: information via mobile appliances or electronic boards about heavy traffic helps to avoid it, appliances also help to find and pay parking.

- Smart health. The possibility to set a meeting with the necessary doctor through on-line schedule is appealing to many patients. And even after the patient leaves the doctor still can get data about his health, or heart beat or else via health bracelets or mobile applications. Even on-line consulting is tested now which will be of high demand for both busy and physically challenged people.

- Open data. Information becomes more open and easier to access. This makes city residents feel informed, integrated. On the official websites there is information about finance, government in persons, official policy and programs of a city.

- Internet of things. When all resources are interconnected one can autopay tax or housing from his bank account. Or municipal snow sensors can activate antifreeze diffusion and even switch on car speed control (with special settings, of course).

Another good example is a website for state and municipal services in Russia [10]. Many state and municipal services can be delivered online or at least applied for online, the website includes all the possible public services. It also acknowledges digital signature.

Smart city concept is a perfect example of an innovative municipal project (Fig. 3). 


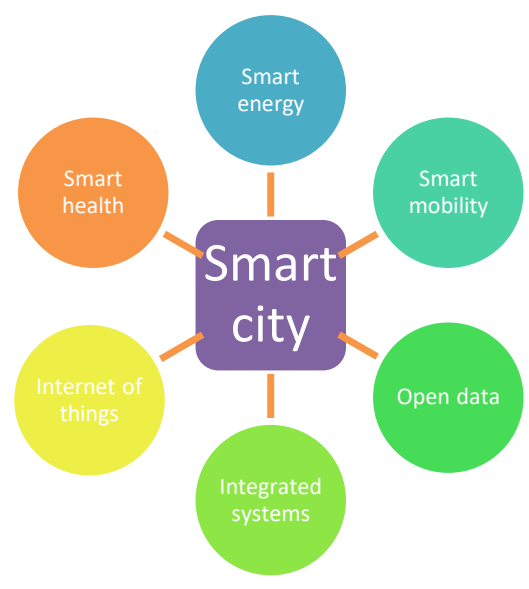

Fig. 3. Main elements of Smart city.

In order to launch the concept all systems should be prepared, some re-done or updated. This can't be done by several people or companies - this is a kind of task only municipal authorities can manage.[11]

The most important is that all elements are interconnected, convenient to control or to use for the residents. Information technologies help to process the data and help to plan and to optimize municipal management.

There are certain benefits from implementing the Smart city (Fig. 4):

- energy economy

- ecology [12]

- social benefits - comfortable environment [13]

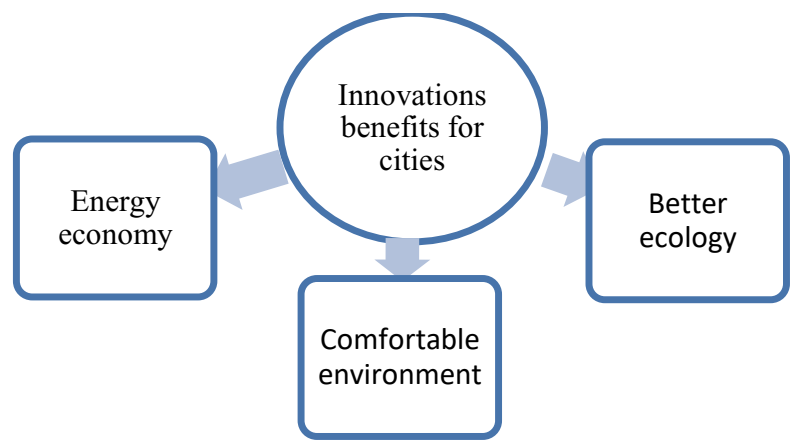

Fig. 4. Innovations benefits for cities.

It is clear, that the Smart city approach meets perfectly well the goals of city management [14].

\section{Discussion}

Of course, implementing technologies needs financing. But this is a long-term investment project which definitely will pay off. Modern people prefer Smart cities, they move to live there and they are ready to pay taxes and to pay for digital municipal and other services.

Besides innovations require a comprehensive approach and policy. Those should be reflected in city development and planning strategies. 


\section{Conclusions}

Cities is a place where more and more people prefer to live. One of the reason is a welldeveloped infrastructure. We live in the era of new informative and digital technologies and it is municipal government duty to make them work for the sake of inhabitants [15]. Innovations in different areas or the concept of Smart city should be an integral part of municipal management in the 21 st century.

\section{References}

1. World Population 2017. Unite Nations. Department of Economic and Social Affairs. Population Division, https://esa.un.org/ unpd/wpp/Publications/Files/WPP2017

2. A. Anton, C.I. Coşoiu, A.M. Georgescu, A New Type of Risk Map for Municipal Sewerage Systems, Procedia Engineering 70, 61-66 (2014)

3. B.N. Silva, M. Khan, K. Han, Sustainable Cities and Society 38, 697-713 (2018)

4. London Land Comission, https://maps.london.gov.uk/LLC/

5. T. Braun, B.C.M. Fung, F. Iqbal, Sustainable Cities and Society 39, 499-507 (2018)

6. Moscow Government, https://data.mos.ru/

7. J. Macke, R.M. Casagrande, J.A.R. Sarate, K.A. Silva, Journal of Cleaner Production 182, 717-726 (2018)

8. Á. Palomo-Navarro, J. Navío-Marco, Smart city networks' governance: The Spanish smart city network case study, Telecommunications Policy (2017)

9. J. Fei, Y. Wang, Y. Yang, Sh. Chen, Q. Zhi, Energy Procedia 104, 165-170 (2016)

10. State and municipal services in Russia www.gosuslugi.ru

11. H. Han, S. Hawken, Culture and Society 12, 1-4 (2018)

12. P. Dissanayake, S. Hettiarachchi, C. Siriwardana, Procedia Engineering 212, 1326-1333 (2018)

13. I. Beretta, Cities 72-A, 115-121 (2018)

14. A. Ferraris, G. Santoro, A. Papa, The cities of the future: Hybrid alliances for open innovation projects, Futures (2018)

15. N. Gardner, L. Hespanhol, Culture and Society 12, 54-61 (2018) 